\title{
Gene expression profiling of the anti-glioma effect of Cilengitide
}

\author{
Manabu Onishi ${ }^{1}$, Kazuhiko Kurozumi ${ }^{1 *}$, Tomotsugu Ichikawa ${ }^{1}$, Hiroyuki Michiue ${ }^{2}$, Kentaro Fujii ${ }^{1}$, Joji Ishida ${ }^{1}$, \\ Yosuke Shimazu', E Antonio Chiocca ${ }^{3}$, Balveen Kaur ${ }^{4}$ and Isao Date ${ }^{1}$
}

\begin{abstract}
Cilengitide (EMD121974), an inhibitor of the adhesive function of integrins, demonstrated preclinical efficacy against malignant glioma. It is speculated that cilengitide can inhibit tumor growth, invasion, and angiogenesis. However, the effects of cilengitide on these processes have not been sufficiently examined. In this study, we investigated the anti-glioma effect of cilengitide using DNA microarray analysis. U87 $\triangle E$ EFR cells (human malignant glioma cell line) were used for this experiment. The cells were harvested after $16 \mathrm{~h}$ of cilengitide treatment, and mRNA was extracted. Gene expression and pathway analyses were performed using a DNA microarray (CodeLink ${ }^{\mathrm{TM}}$ Human Whole Genome Bioarray). The expression of 265 genes was changed with cilengitide treatment. The expression of 214 genes was up-regulated by more than 4-fold and the expression of 51 genes was down-regulated by more than 4-fold compared to the controls. In pathway analysis, "apoptotic cleavage of cellular proteins" and "TNF receptor signaling pathway" were over-represented. Apoptotic-associated genes such as caspase 8 were upregulated. Gene expression profiling revealed more detailed mechanism of the anti-glioma effect of cilengitide. Genes associated with apoptosis were over-represented following cilengitide treatment.
\end{abstract}

Keywords: Glioma, Integrin, Cilengitide, Gene expression profiling, Apoptosis

\section{Introduction}

Gliomas are the most frequent primary intracranial neoplasm in adults and are invariably fatal. The median survival of aggressively treated patients with glioblastoma is approximately 14.6 months (Stupp \& Weber 2005). The resistance of gliomas to the conventional therapeutic regimen of surgery, radiotherapy, and chemotherapy has prompted many investigators to seek novel therapeutic approaches for this fatal disease (Chatterjee et al. 2000). Moreover, alterations of the epidermal growth factor receptor $(E G F R)$ gene are common in some forms of cancer and the most frequent is a deletion of exons 2-7. It was previously reported that this mutant receptor, called $\triangle \mathrm{EGFR}$, confers enhanced tumorigenicity on glioblastoma cells through elevated proliferation and reduced apoptotic rates in vivo (Narita et al. 2002).

\footnotetext{
* Correspondence: kkuro@md.okayama-u.ac.jp

'Department of Neurological Surgery, Okayama University Graduate School of Medicine, Dentistry and Pharmaceutical Sciences, 2-5-1, Shikata-cho, Kitaku, Okayama 700-8558, Japan

Full list of author information is available at the end of the article
}

Integrins control the attachment of cells to the extracellular matrix (ECM) and participate in cellular defense against genotoxic assaults (Hynes 2002). Integrins are expressed in tumor cells and tumor endothelial cells (Varner \& Cheresh 1996a; Varner \& Cheresh 1996b; Varner et al. 1995), and they play important roles in angiogenesis and invasion in glioma (Friedlander et al. 1995; Brooks et al. 1994a; Brooks et al. 1994b). $\alpha v \beta 3$ and $\alpha v \beta 5$ integrins regulate cell adhesion (HodivalaDilke et al. 2003; Leavesley et al. 1992), and inhibitors of these integrins suppress tumor growth in certain preclinical models (MacDonald et al. 2001). Therefore, integrins have attracted attention as potential therapeutic targets in glioma.

Currently, $\alpha v \beta 3$ and $\alpha v \beta 5$ integrin antagonists including cilengitide (EMD121974), which is a cyclic RGDcontaining peptide (Xiong et al. 2001), are in clinical trials. This drug is reportedly able to penetrate the blood brain barrier (BBB) in vivo (Nabors et al. 2007). Cilengitide induces anoikis in angiogenic blood vessels and brain tumor cells in vitro (Oliveira-Ferrer et al. 2008; Alghisi et al. 2009); however, the mechanisms 
underlying its cytotoxic effects are not completely understood.

There have been no microarray studies to date that examined the changes in gene expression after cilengitide treatment. U87 $\triangle E G F R$ cells were previously shown to have increased tumorigenicity via elevated proliferation and reduced apoptosis compared to U87 cells, which cause a more aggressive phenotype than that of the parental cell line (Narita et al. 2002). In this study, we profiled and examined the gene expression of over 57000 genes using the most comprehensive GeneChip microarrays available (CodeLink ${ }^{\mathrm{TM}}$ Human Whole Genome Bioarray), and identified differentially expressed genes between untreated glioma cells (U87 $\triangle E$ EFR) and cilengitide-treated glioma cells to reveal more detail mechanism of anti-glioma effect of cilengitide.

\section{Materials and methods}

\section{Glioma cell line and drug}

Glioma cell lines, U87 $\triangle E G F R$, were seeded in tissue culture dishes (BD Falcon, Franklin Lakes, NJ, USA) and cultured in Dulbecco's Modified Eagle's Medium (DMEM) supplemented with $10 \%$ fetal bovine serum (FBS), $100 \mathrm{U}$ penicillin, and $0.1 \mathrm{mg} / \mathrm{mL}$ streptomycin. U87MG, Gli36 $\Delta 5$, and U251 human glioma cells were also prepared and maintained as described previously (Kambara et al. 2005). Cilengitide was generously provided by Merck KgaA and the National Cancer Institute, National Institutes of Health.

\section{Cell surface immunofluorescence assay}

U87 $\triangle$ EGFR cells were seeded on 4 Chamber Polystyrene Vessel Tissue Culture Treated Glass Slides (BD Falcon, Franklin Lakes, NJ, USA) and incubated overnight. For immunofluorescence, the cells were fixed in $4 \%$ paraformaldehyde in phosphate-buffered saline (PBS) for $15 \mathrm{~min}$. After the cells were fixed, they were rinsed 3 times with PBS. Nonspecific binding was blocked by incubation in a blocking buffer containing $2 \%$ bovine serum albumin in PBS for $30 \mathrm{~min}$ at room temperature. The cells were incubated overnight at $4{ }^{\circ} \mathrm{C}$ with a mouse anti-human integrin $\alpha v \beta 3$ monoclonal antibody (Millipore Corporation, Billerica, MA, USA) or mouse anti-human integrin $\alpha \mathrm{v} \beta 5$ monoclonal antibody (Abcam, Cambridge, UK) diluted 1:100 in blocking buffer. The cells were washed 3 times in blocking buffer for 5 min before incubation with a secondary anti-mouse CY3-conjugated antibody (Jackson ImmunoResearch Laboratories, Inc., West Grove, PA, USA) diluted 1:300 in blocking buffer for $2 \mathrm{~h}$ at room temperature in the dark. After 3 washes in PBS, the cells were counterstained with 4', 6-diamino-2phenylindole (DAPI; 1:500) (Invitrogen, Carlsbad, CA, USA) $(100 \mathrm{ng} / \mathrm{mL}$ ) for $20 \mathrm{~min}$ at room temperature. The slides were washed 3 times in PBS and mounted.

\section{Water-soluble tetrazolium-1 assay}

A water-soluble tetrazolium (WST)-1 assay (Roche Diagnostics) was performed according to the manufacturer's instructions. Briefly, cells treated with saline (control cells) or Cilengitide $(1.0 \mu \mathrm{M})$ (Cilengitide was generously provided by Merck KGaA and the National Cancer Institute, $\mathrm{NIH}$ ) were plated in a 96-well plate at a concentration of 25,000 cells $/ \mathrm{mL}$. Cell survival was measured at the indicated time points by adding $10 \mu \mathrm{L}$ of a 1:3 (v/v) diluted ready-to-use WST-1 cell proliferation reagent stock solution (Roche, Mannheim). The samples were incubated for 60-240 min and absorption was measured with an MTP-120 micro plate reader (CORONA ELECTRIC Co., Ibaragi, Japan) at $450 \mathrm{~nm}$ wavelength using a $620 \mathrm{~nm}$ reference filter. After subtraction of the background absorption, the mean value of the untreated control cells was set as $100 \%$.

\section{Microarray analysis}

U87 $\triangle$ EGFR cells treated with cilengitide $(1.0 \mu \mathrm{M}$ for $16 \mathrm{~h}$ ) and untreated control U87 $\triangle E G F R$ cells were analyzed using a CodeLink ${ }^{\mathrm{TM}}$ Human Whole Genome Bioarray (Applied Microarrays, Inc., Tempe, AZ, USA). We entrusted the microarray analyses to Filgen, Inc. (Nagoya, Japan). Briefly, for each bioarray, $10 \mu \mathrm{g}$ of cRNA in a $25 \mu \mathrm{L}$ total volume were added to $5 \mu \mathrm{L}$ of $5 \times$ fragmentation buffer, which was then incubated at $94^{\circ} \mathrm{C}$ for $20 \mathrm{~min}$. Thereafter, $10 \mu \mathrm{g}$ of fragmented cRNA, $78 \mu \mathrm{L}$ of hybridization buffer component $\mathrm{A}$, and $130 \mu \mathrm{L}$ of hybridization buffer component $\mathrm{B}$ were added, and the final volume was brought up to $260 \mu \mathrm{L}$ with water. The resultant hybridization reaction mixture was incubated at $90^{\circ} \mathrm{C}$ for $5 \mathrm{~min}$, after which $250 \mu \mathrm{L}$ were slowly injected into the input port of each array, and the ports were sealed with sealing strips. The bioarrays were then incubated for $18 \mathrm{~h}$ at $37^{\circ} \mathrm{C}$ while shaking at $300 \mathrm{rpm}$. A consistent hybridization time was maintained for comparative experiments. Following the incubation, the bioarrays were washed with 0.75 TNT buffer $(0.10 \mathrm{M}$ Tris- $\mathrm{HCl}, \mathrm{pH} 7.6$, $0.15 \mathrm{M} \mathrm{NaCl}, 0.05 \%$ Tween 20 ) and incubated at $46^{\circ} \mathrm{C}$ for $1 \mathrm{~h}$. Each slot of the small reagent reservoir was then filled with $3.4 \mathrm{~mL}$ of Cy5-Streptavidin working solution, and the array was incubated at $25^{\circ} \mathrm{C}$ for another $30 \mathrm{~min}$. Thereafter, the bioarrays were washed 4 times for 5 min each with $1 \times$ TNT buffer at $25^{\circ} \mathrm{C}$, rinsed twice in $0.1 \times \mathrm{SSC}$ (Ambion, Austin, TX, USA) $/ 0.05 \%$ Tween 20 for $30 \mathrm{~s}$ each, and immediately dried by centrifugation for $3 \mathrm{~min}$ at $25^{\circ} \mathrm{C}$. Finally, the arrays were scanned using a GenePix4000B Array Scanner (Molecular Devices, Sunnyvale, CA, USA). A gene was defined as being upregulated when the cilengitide treatment/control average intensity ratio was $>4.0$, and downregulated when the cilengitide treatment/control ratio was $<0.25$. We performed pathway analysis on the genes that expressed increase and decrease using 
Microarray Data Analysis Tool Ver3.2 (Filgen, Inc). The data were extracted using the following criteria: Zscore $>0$ and P-value $<0.05$ (Ichii et al. 2011; Yoshino et al. 2011).

\section{Quantitative reverse-transcription polymerase chain reaction (QRT-PCR)}

Total RNA was isolated from cultured U87 $\triangle E$ EFR cells treated with cilengitide $(1.0 \mu \mathrm{M}$ for $16 \mathrm{~h})$ and untreated control U87 $\triangle$ EGFR cells using an RNeasy ${ }^{\circledR}$ Mini Kit (QIAGEN, Hilden, Germany). In vivo, that RNA was extracted from the brain tumor tissue of rat that had been treated with PBS or with Cilengitide with the use of TRIZOL reagent (Invitrogen, Carlsbad, CA, USA), according to the manufacturer's instructions. Those RNA were reverse transcribed with oligo dT primers using the SuperScript III First-Strand Synthesis System for RT-PCR (Invitrogen, Carlsbad, CA, USA) according to manufacturer's instructions. Primers specific for each gene were designed using Primer 3 Plus Software (http:// www.bioinformatics.nl/cgi-bin/primer3plus/primer3plus.cgi) and synthesized by Invitrogen. The resulting cDNA was amplified by PCR using gene-specific primers and the 7300 Real Time PCR system (Applied Biosystems, Foster City, CA, USA) and QuantiTectTM SYBR ${ }^{\circledR}$ Green PCR Kit (QIAGEN, Hilden, Germany). A log-linear relationship between the amplification curve and quantity of cDNA in the range of 1-1000 copies was observed. The cycle number at the threshold was used as the threshold cycle $(\mathrm{Ct})$. The different expression of mRNA was detected from $2-\Delta \Delta C t$ using the 7300 Real Time PCR System with Sequence Detection Software (version 1.4; Applied Biosystems, Foster City, CA, USA). The amount of cDNA in each sample was normalized to the crossing point of the housekeeping gene glyceraldehyde 3-phosphate dehydrogenase (GAPDH). The following thermal cycling parameters were used: denaturation at $95^{\circ} \mathrm{C}$ for $10 \mathrm{~min}$ followed by 45 cycles at $94^{\circ} \mathrm{C}$ for $15 \mathrm{~s}, 50^{\circ} \mathrm{C}$ for $30 \mathrm{~s}$, and $72^{\circ} \mathrm{C}$ for $30 \mathrm{~s}$. The relative mRNA upregulation for each gene in the control was calculated using their respective crossing points with the following formula, as previously described (Kurozumi et al. 2007):

$F=2^{(T H-T G)-(O H-O G)}$ where, $F=$ fold difference, $T=$ control, $O=$ treated cell or tumor, $H=$ housekeeping (GAPDH), and $G=$ gene of interest.

CASPASE 8 primers

CASP8 F (forward), 5-TGCAGGGTCTCACTCTGTTG-3 CASP8 R (reverse), 5-TTGATTTTGGAGGGATCTCG-3 protein kinase $C$, zeta primers

PKCZ F (forward), 5-GTTATCGATGGGATGGATGG-3 PKCZ R (reverse), 5-GCACCAGCTCTTTCTTCACC-3 GAPDH primers

GAPDH F (forward), 5- GAGTCAACGGATTTGGTCGT-3 GAPDH R (reverse), 5-TTGATTTTGGAGGGATCTCG-3

\section{Activity assay of caspase- $3 / 7$ and -8}

Caspase-3/7 and -8 activity levels were measured using CellEvent $^{\mathrm{TM}}$ Caspase-3/7 Green Detection Reagent (Invitrogen, Carlsbad, CA, USA) and the colorimetric protease assay kit (MBL, CA, USA), respectively, according to the protocol recommended by the manufacturer. Briefly, cells (5,000 cells per well) were plated in 96-well plates in triplicate and treated with cilengitide. Cilengitide $(1.0 \mu \mathrm{M})$ was added to the medium after $24 \mathrm{~h}$ of incubation. The caspase solution was added at $16 \mathrm{~h}$ after adding cilengitide. After incubation with these substrates, the absorbance of each well was measured using a microplate reader.

\section{TdT-mediated dUTP nick end labeling (TUNEL) assay}

U87 $\triangle$ EGFR cells were seeded in 6 -well plates $\left(1.0 \times 10^{4}\right.$ cells/well) and cultured in DMEM supplemented with $10 \%$ FBS. Cilengitide $(10 \mu \mathrm{M})$ was added to the medium after $24 \mathrm{~h}$ of incubation. After incubation for $16 \mathrm{~h}$ at $37^{\circ} \mathrm{C}$, the cells were examined for morphological changes. Apoptotic cells were detected with the In Situ Cell Death Detection Kit (Roche, Basel, Switzerland) according to the manufacturer's instructions.

\section{Immunoblot analysis}

Using immunoblot analysis, we examined whether treatment with cilengitide induced caspase activation via caspase 8 and caspase 3. Western blotting was carried out at a high stringency, essentially as described previously (Kurozumi et al. 2004; Michiue et al. 2005a; Michiue et al. 2005b). The harvested cells with treated each concentration of drug $(0.1,1.0,10 \mu \mathrm{M}$ : $16 \mathrm{hr})$ or each time course $(8,16,24 \mathrm{hr}: 1 \mu \mathrm{M})$ were lysed by a sonicator in a boiled buffer containing $1 \%$ SDS. The cell lysate $(50 \mu \mathrm{g})$ was subjected to SDS-PAGE and transferred to nitrocellulose membranes (Hybond ECL, GE Healthcare UK Ltd, England). The blots were probed with each primary antibody. Specific bands were visualized with an enhanced chemiluminescence detection kit (GE Healthcare UK Ltd, England). The following primary rabbit polyclonal antibodies were used: anti-human caspase 8 (1:500; ab44976, abcam, Inc., UK), anti-human caspase 3 (1:250; ab32125, abcam, Inc., UK), and $\beta$-actin (1:1000; Sigma-Aldrich, St. Louis, MO, USA).

\section{Brain xenografts}

All experimental animals were housed and handled in accordance with the guidelines of the Okayama University Animal Research Committee. Before implantation, 85-90\% confluent U87 $\triangle$ EGFR cells were trypsinized, rinsed with DMEM supplemented with $10 \%$ FBS, and centrifuged at $100 \times g$ for $5 \mathrm{~min}$; the resulting pellet was resuspended in PBS, and the cell concentration was adjusted to $1.0 \times 10^{5}$ cells $/ \mu \mathrm{L}$. U87 $\triangle$ EGFR cells $(5 \mu \mathrm{L})$ were injected into athymic rats (F344/N-nu/nu; CLEA Japan, 
Inc., Tokyo, Japan). The animals were anesthetized and placed in stereotactic frames (Narishige, Tokyo, Japan) with their skulls exposed. Tumor cells were injected with a Hamilton syringe (Hamilton, Reno, NV, USA) into the right frontal lobe $(4 \mathrm{~mm}$ lateral and $1 \mathrm{~mm}$ anterior to the bregma at a depth of $4 \mathrm{~mm}$ ) and the syringe was slowly withdrawn after 5 min to prevent reflux. The skulls were then cleaned, the holes were sealed with bone wax, and the incision was sutured. Cilengitide or PBS was administered 3 times/week intraperitoneally $(1 \mathrm{mg} / 500 \mu \mathrm{L}$ PBS), starting on day 5 after tumor cell implantation. To assess the gene expression of caspase 8 with QRT-PCR, athymic rats harboring U87 $\triangle E G F R$ brain tumors were sacrificed at 18 days after tumor implantation. The tumorbearing right hemispheres of the brains were excised and processed for RNA. For measurements of tumor cell apoptosis, athymic rats were sacrificed at 18 days after tumor implantation. The brains were removed and fixed in $4 \%$ paraformaldehyde for at least $24 \mathrm{~h}$.

\section{TUNEL staining in vivo}

Snap-frozen tissue samples were embedded in optimal cutting temperature solution (Sakura Finetek Inc., Torrance, CA, USA) for cryosectioning, and 16- $\mu \mathrm{m}$ cryostat sections were cut. Apoptotic tumor cells were detected using the In Situ Cell Death Detection Kit (Roche, Basel, Switzerland) according to the manufacturer's instructions.

\section{Statistical analysis}

Student's $t$ test was used to test for statistical significance. Data are presented as the mean \pm standard error. All statistical analyses were performed with the use of SPSS statistical software (version 14.0; SPSS, Inc., Chicago, IL, USA).

\section{Results}

Immunohistochemical analysis of $\operatorname{av} \beta 3$ and $\operatorname{av} \beta 5$ integrins expression in U87 $\triangle E G F R$ cells

Immunofluorescence assays were conducted to determine the expression of $\alpha v \beta 3$ and $\alpha v \beta 5$ integrins in U87 $\triangle E G F R$ cells. Cultured U87 $\triangle E G F R$ cells were immunopositive for $\alpha v \beta 3$ and $\alpha v \beta 5$ integrins (Figure 1a, b).

\section{Cytotoxic effects of cilengitide on the U87 $\triangle E$ EFR glioma cell line in vitro}

The direct effects of cilengitide were investigated on glioma cells in vitro. U87 $\triangle E$ EFR cells were incubated with cilengitide at concentrations of $0-10 \mu \mathrm{M} ; 16 \mathrm{~h}$ later, the cells were subjected to the WST-1 proliferation/viability assay. Cell viability after $16 \mathrm{~h}$ of incubation was decreased in cell cultures treated with cilengitide, reaching statistical significance at $1 \mu \mathrm{M}$ or higher (Figure 1c). In addition, cell viability was decreased in cell cultures treated with $1 \mu \mathrm{M}$ cilengitide, reaching statistical significance at $16 \mathrm{~h}$ or later
(Figure 1d). These cells became sensitive to cilengitide in a concentration- and time-dependent manner.

\section{Microarray analysis}

Our cell viability assay showed that the decrease in the number of viable cells treated with $1 \mu \mathrm{M}$ cilengitide reached statistical significance at $16 \mathrm{~h}$. At that time point, differential gene expression was compared between cilengitide-treated U87 $\triangle$ EGFR cells and untreated control U87 $\triangle$ EGFR cells ( $>4$ fold change, $<0.25$ fold change) (Figure 2a, b). There were 265 differentially expressed genes between cilengitide-treated U87 $\triangle$ EGFR cells and control U87 $\triangle$ EGFR cells with 214 upregulated and 51 downregulated. We further characterized the functional significance of the dysregulated genes using pathway analysis. For the upregulated genes, 20 significantly enriched pathways were identified for the differentially expressed genes between cilengitide-treated U87 $\triangle E G F R$ cells and control cells (Table 1). For the downregulated genes, 7 significantly enriched pathways were identified (Table 2). Especially for the upregulated genes, the significantly enriched molecular pathways included apoptotic cleavage of cellular proteins, FasL/CD95L signaling, TNF receptor signaling pathway, and ceramide signaling pathway. Caspase 8, desmoplakin, and protein kinase C, zeta were included in these pathways and upregulated.

\section{Validation of the microarray results}

To confirm the reliability of the results from the microarray analysis, caspase 8 , protein kinase $\mathrm{C}$, zeta, were verified by QRT-PCR analysis (Figure $3 \mathrm{a}, \mathrm{b}$ ). The relative expression of caspase 8 and protein kinase $C$, zeta in U87 $\triangle E$ EFR cells incubated with cilengitide was significantly higher than those of the cells without cilengitide by 2.25 -fold and 5.78-fold, respectively $(\mathrm{P}<0.05)$.

\section{Capsase activation assay and caspase expression in western blotting}

U87 $\triangle$ EGFR cells were treated with $0.5 \mu \mathrm{M}$ cilengitide for $16 \mathrm{~h}$. Cilengitide-induced caspase- 8 activity was detected with the colorimetric protease assay kit. The relative absorbance (RA) of U87 $\triangle E G F R$ cell clusters were higher than control $(0.27 \pm 0.01$ RA vs. $0.36 \pm 0.01$ RA, respectively; $P<0.05$ ) (Figure $3 \mathrm{a}$ ). U87 $\triangle \mathrm{EGFR}$ cells were loaded with $8 \mu \mathrm{M}$ CellEvent ${ }^{\mathrm{TM}}$ Caspase-3/7 Green Detection Reagent then treated with the same concentration. Cilengitide-induced caspase $3 / 7$ activity was detected with the CellEvent ${ }^{\mathrm{TM}}$ Caspase-3/7 Green Detection Reagent. The relative Fluorescence Unit (RFU) of U87 $\triangle E G F R$ cell clusters were higher than control $(35.4 \pm 0.78$ RFU vs. $16.5 \pm 0.5$ RFU, respectively; $P<0.05$ ) (Figure 3b). The next series of experiments was designed to examine whether treatment with cilengitide induced caspase activation in other cell lines. Caspase 


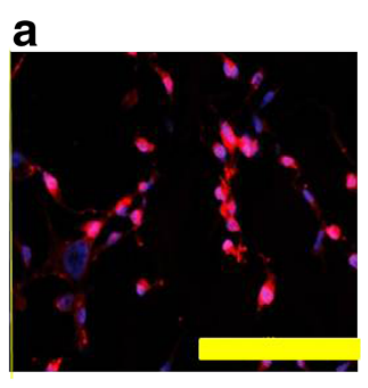

C

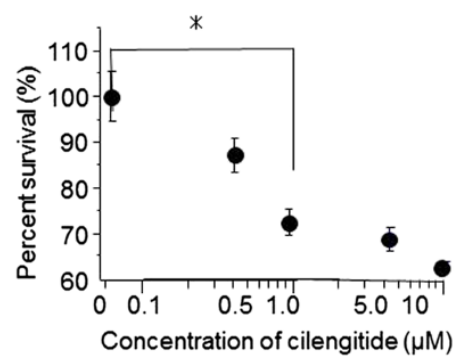

b

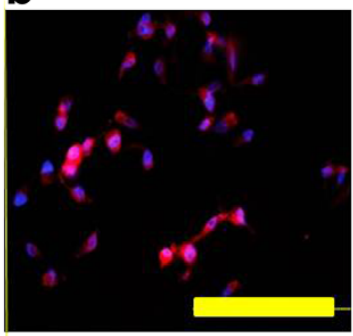

d

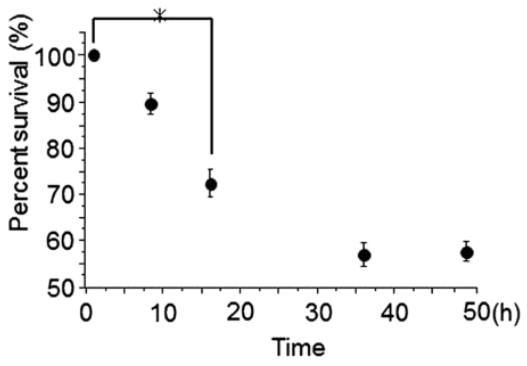

Figure 1 Immunohistochemical analysis of the av $\beta 3$ and $\operatorname{av} \beta 5$ integrins, and WST-1 proliferation/viability assay. Cultured U87 $\triangle E G F R$ cells were immunopositive for $\operatorname{av} \beta 3(\mathbf{a})$ and $\operatorname{av} \beta 5$ (b) integrins (Scale bar $=100 \mu \mathrm{m}$ ). Cilengitide reduced the number of viable cells in a dose and time -dependent manner $\left({ }^{*} \mathrm{P}<0.05\right)($ mean $\pm \mathrm{SE})(\mathbf{c}, \mathbf{d})$.

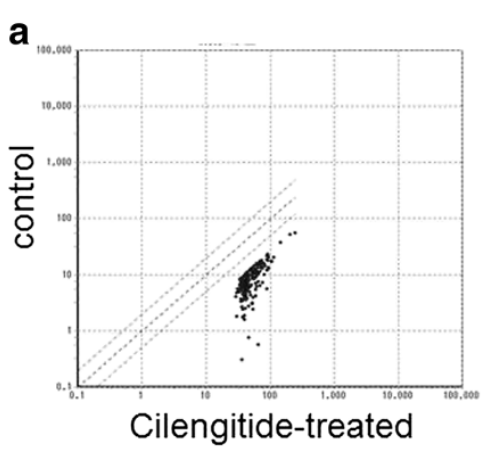

C

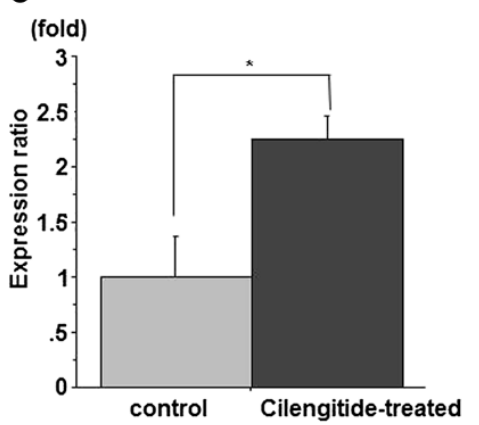

b

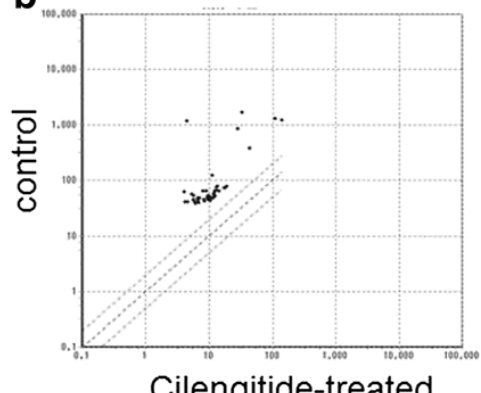

Cilengitide-treated

d

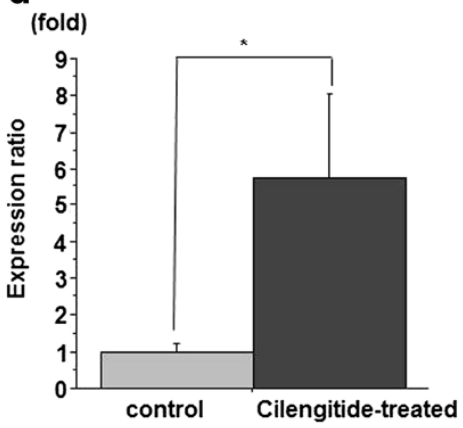

Figure 2 Microarray and QRT-PCR analyses of cilengitide-treated cells. There were 265 differentially expressed genes between cilengitidetreated U87 EEGFR cells and untreated control U87 $E$ EGFR cells with 214 upregulated (a) and 51 downregulated (b) genes. Caspase-8 (c) and protein kinase $C$, zeta $(\mathbf{d})$ were significantly increased by cilengitide treatment $\left({ }^{*} \mathrm{P}<0.05\right)$ ( $m e a n \pm S E, n=3$ ). 
Table 1 Significantly enriched pathways between cilengitide-treated U87 $\triangle E G F R$ and control

\begin{tabular}{|c|c|c|c|c|}
\hline Pathwayname & Entrez gene ID & Gene symbol & P-value & Z score \\
\hline $\begin{array}{l}\text { NF-kB activation through FADD/RIP-1 pathway } \\
\text { mediated by caspase- } 8 \text { and }-10\end{array}$ & 23586,841 & DDX58, CASP8 & 0.004 & 6.358 \\
\hline Organic cation/anion/zwitterion transport & 55867,6580 & SLC22A11, SLC22A1 & 0.005 & 6.084 \\
\hline Cell adhesion molecules (CAMs) & $1364,4359,941,: 965$ & CLDN4, MPZ, CD80, CD58 & 0.014 & 3.213 \\
\hline NOSIP mediated eNOS trafficking & 4846 & NOS3 & 0.022 & 8.034 \\
\hline EPHB forward signaling & 8867,8997 & SYNJ1, KALRN & 0.026 & 3.585 \\
\hline Apoptotic cleavage of cellular proteins & 1832,841 & DSP, CASP8 & 0.034 & 3.262 \\
\hline Regulation of RAC1 activity & 2059,8997 & EPS8, KALRN & 0.036 & 3.204 \\
\hline $\begin{array}{l}\text { Activation, myristolyation of BID and translocation } \\
\text { to mitochondria }\end{array}$ & 841 & CASP8 & 0.037 & 5.593 \\
\hline Fatty acids & 1580 & CYP4B1 & 0.037 & 2.177 \\
\hline Signaling in Immune system & $\begin{array}{l}\text { 23586, 3429, 6196, 6672, :841, } \\
84433,941\end{array}$ & $\begin{array}{l}\text { DDX58, IFI27, RPS6KA2, SP100, } \\
\text { CASP8, } \\
\text { CARD11, CD80 }\end{array}$ & 0.037 & 3.149 \\
\hline LKB1 signaling events & 2011,57521 & MARK2,RPTOR & 0.037 & 2.631 \\
\hline ErbB1 downstream signaling & $2059,4086,5590$ & EPS8, SMAD1, PRKCZ & 0.039 & 4.964 \\
\hline FasL/CD95L signaling & 841 & CASP8 & 0.044 & 4.964 \\
\hline NOSTRIN mediated eNOS trafficking & 4846 & NOS3 & 0.044 & 4.964 \\
\hline Organic anion transport & 55867 & SLC22A11, & 0.044 & 4.964 \\
\hline Pyrimidine biosynthesis & 7372 & UMPS & 0.044 & 4.964 \\
\hline Release of elF4E & 57521 & PRTOR & 0.044 & 4.964 \\
\hline Ceramide signaling pathway & 5590,841 & PRKCZ, CASP8 & 0.046 & 2.899 \\
\hline TNF receptor signaling pathway & 5590,841 & PRKCZ, CASP8 & 0.046 & 2.899 \\
\hline Thromboxane A2 receptor signaling & 4846,5590 & NOS3, PRKCZ & 0.048 & 2.853 \\
\hline
\end{tabular}

activation was analyzed by using immunoblotting. Caspase 3 is produced as a $32-\mathrm{kDa}$ proenzyme and cleaved into its $17 \mathrm{kDa}$ active form. In U251, Gli36 $\Delta 5$, U87MG, and U87 $\triangle$ EGFR cells, cilengitide treatment induced the activated form of caspase 3 . Caspase 8 is produced as a $55-\mathrm{kDa}$ proenzyme and cleaved into its $30 \mathrm{kDa}$ and $15 \mathrm{kDa}$ active form. In U251, Gli36 $\Delta 5$, U87MG, and U87 $\triangle E G F R$ cells, cilengitide induced the activated form of caspase 9. Immunoblot analysis revealed that caspases 3 and 8 were processed in both cells in response to cilengitide in a concentration- (Figure 3c) and time-dependent manner (Figure 3d).

\section{Apoptosis analysis}

To confirm the apoptosis of the deformed glioma cells treated with cilengitide, the cells were stained with the In Situ Cell Death Detection Kit using TMR red. Originally, U87 $\triangle \mathrm{EGFR}$ cells in culture were composed of bipolar cells; however, they became spherical and agglutinated when cilengitide was added to the culture medium. Some of these deformed cells detached from the plate (Figure 4a, b, c, d). These detached U87 $\triangle E$ EFF cells were not viable, as indicated by unsuccessful attempts of re-plating these cells in medium that did not contain cilengitide. U87 $\triangle E G F R$ cell clusters were positive cells

Table 2 Downregulated pathway

\begin{tabular}{|c|c|c|c|c|}
\hline Pathway name & Entrez gene ID & Gene symbol & P-value & Z score \\
\hline Sphingolipid metabolism & 8879 & SGPL1 & 0.006 & 16.049 \\
\hline BH3-only proteins associate with and inactivate anti-apoptotic BCL-2 members & 598 & BCL2L1 & 0.015 & 8.496 \\
\hline G alpha (s) signalling events & 134860,4160 & TAAR9, MC4R & 0.022 & 3.717 \\
\hline Syndecan-3-mediated signaling events & 4160 & MC4R & 0.032 & 5.52 \\
\hline Sphingosine 1-phosphate (S1P) pathway & 8879 & SGPL1 & 0.038 & 5.036 \\
\hline Signaling events mediated by the Hedgehog family & 91653 & $\mathrm{BOC}$ & 0.042 & 4.771 \\
\hline Pentose phosphate pathway & 8277 & TKTL1 & 0.045 & 4.54 \\
\hline
\end{tabular}




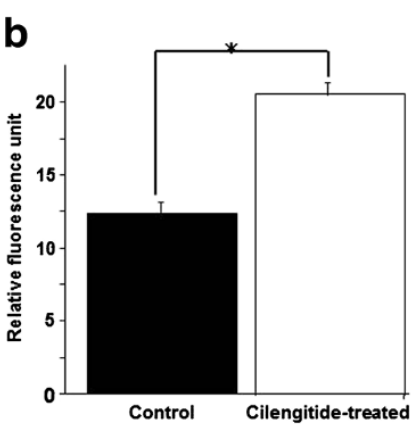

d

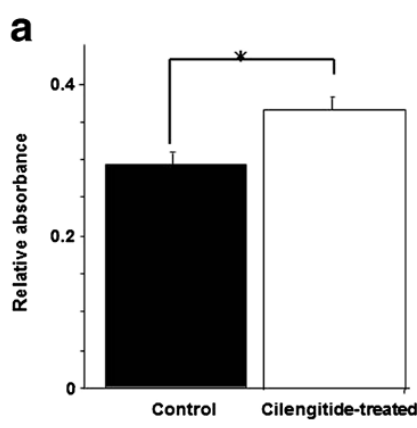

C

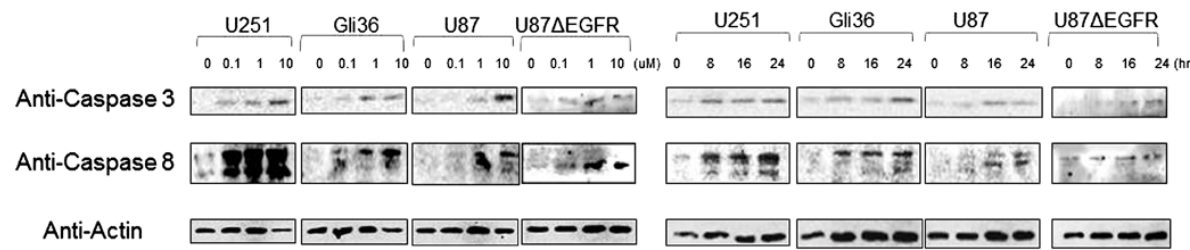

Figure 3 QRT-PCR analysis and activation of caspase-3/7 and -8 in cilengitide-treated cells. U87 $\Delta E G F R$ cells were treated with $0.5 \mu M$ cilengitide for $16 \mathrm{~h}$ with the colorimetric protease assay kit. For the activity of caspase-8, the relative absorbance (RA) of U87 $\triangle E G F R$ cell clusters were higher than control $(0.27 \pm 0.01$ RA vs. $0.36 \pm 0.01$ RA, respectively; $P<0.05)$ (a). Cilengitide-induced apoptosis was also detected with the CellEvent ${ }^{\mathrm{TM}}$ Caspase-3/7 Green Detection Reagent. The RFU of U87 $\Delta$ EGFR cell clusters were higher than control (35.4 $\pm 0.78 \mathrm{RFU}$ vs. $16.5 \pm 0.5 \mathrm{RFU}$, respectively; $P<0.05)(\mathbf{b})$. Immunoblot analysis revealed that caspases 3 and 8 were processed in all examined cell lines following treatment with cilengitide in a concentration- (c) and time-dependent manner (d).

compared to control $(35.4 \pm 0.78$ vs. $16.5 \pm 0.5$, respectively; $P<0.05$ ) (Figure $4 \mathrm{e}$ ).

\section{Cilengitide induces apoptosis in U87 $\triangle$ EGFR-derived xenografts}

The effect of cilengitide on the induction of apoptosis was examined in U87 $\triangle E G F R$-derived xenografts. At 5 days after implantation, the rats were administered cilengitide ( $1 \mathrm{mg} / 500 \mu \mathrm{L}$ PBS) 3 times/week intraperitoneally, and the rats were killed at 18 days after implantation. Caspase 8 gene expression was analyzed with QRT-PCR and the induction of apoptosis in frozen sections of the U87 $\triangle \mathrm{EGFR}$ xenografts was examined under a fluorescent microscope. QRT-PCR revealed a statistically significant 10.1-fold increase in caspase 8 gene expression in Cilengitide treated tumors compared with control tumors (Figure 4f). A subpopulation of apoptotic cells were visualized by TUNEL treatment using the In Situ Cell Death Detection Kit (apoptotic cells: TMR red; nuclei: DAPI, blue). The control sections exhibited a smaller amount of red fluorescent cells (Figure 4g), whereas more scattered red fluorescent cells were observed in the cilengitidetreated xenografts (Figure 4h). To quantify the cytotoxic effect of cilengitide, the number of apoptotic cells per high-power field (HPF) in U87 $\triangle E G F R$ control xenografts and U87 $\triangle E G F R$ cilengitide-treated xenografts were assessed (Figure 4i). The number of apoptotic cells in U87 $\triangle \mathrm{EGFR}$ cilengitide-treated xenografts $(26.2 \pm 3.8$ cells/HPF) was significantly higher than in U87 $\triangle$ EGFR control xenografts $(1.40 \pm 0.6$ cells/HPF $)(\mathrm{P}<0.05)$. The average percentage of apoptotic cells was $5 \%$ in U87 $\triangle \mathrm{EGFR}$ cilengitide-treated xenografts (Figure $4 \mathrm{j}$ ).

\section{Discussion}

Cilengitide treatment induced morphological changes and cell detachment in glioma cells incubated in dishes and decreased cell viability in a dose and time-dependent manner. Microarray analysis showed that the expression of 265 genes was changed after cilengitide treatment. The expression of 214 genes was up-regulated 4-fold more and the expression of 51 genes was down-regulated to less than $25 \%$ of control and apoptotic signaling pathways were over-represented in the pathway analysis. In addition to the effect of cilengitide in cultured cells, cilengitide also induced apoptosis in U87 $\triangle E G F R$-derived xenografts, suggesting that the induction of apoptosis also occurs in vivo.

\section{Cytotoxic effect of Cilengitide}

Cilengitide is an angiogenesis inhibitor that targets the integrins $\alpha v \beta 3$ and $\alpha v \beta 5$, which bind to ECM proteins such as vitronectin and fibronectin (Burke et al. 2002; Albert et al. 2006). Because integrins are expressed in tumor cells and tumor endothelial cells (Varner \& Cheresh 1996a), it is speculated that cilengitide can inhibit tumor growth by at least 2 mechanisms: by targeting the tumor cells directly and by inhibiting tumor angiogenesis (Tucker 2003; Oliveira-Ferrer et al. 2008; Chatterjee et al. 


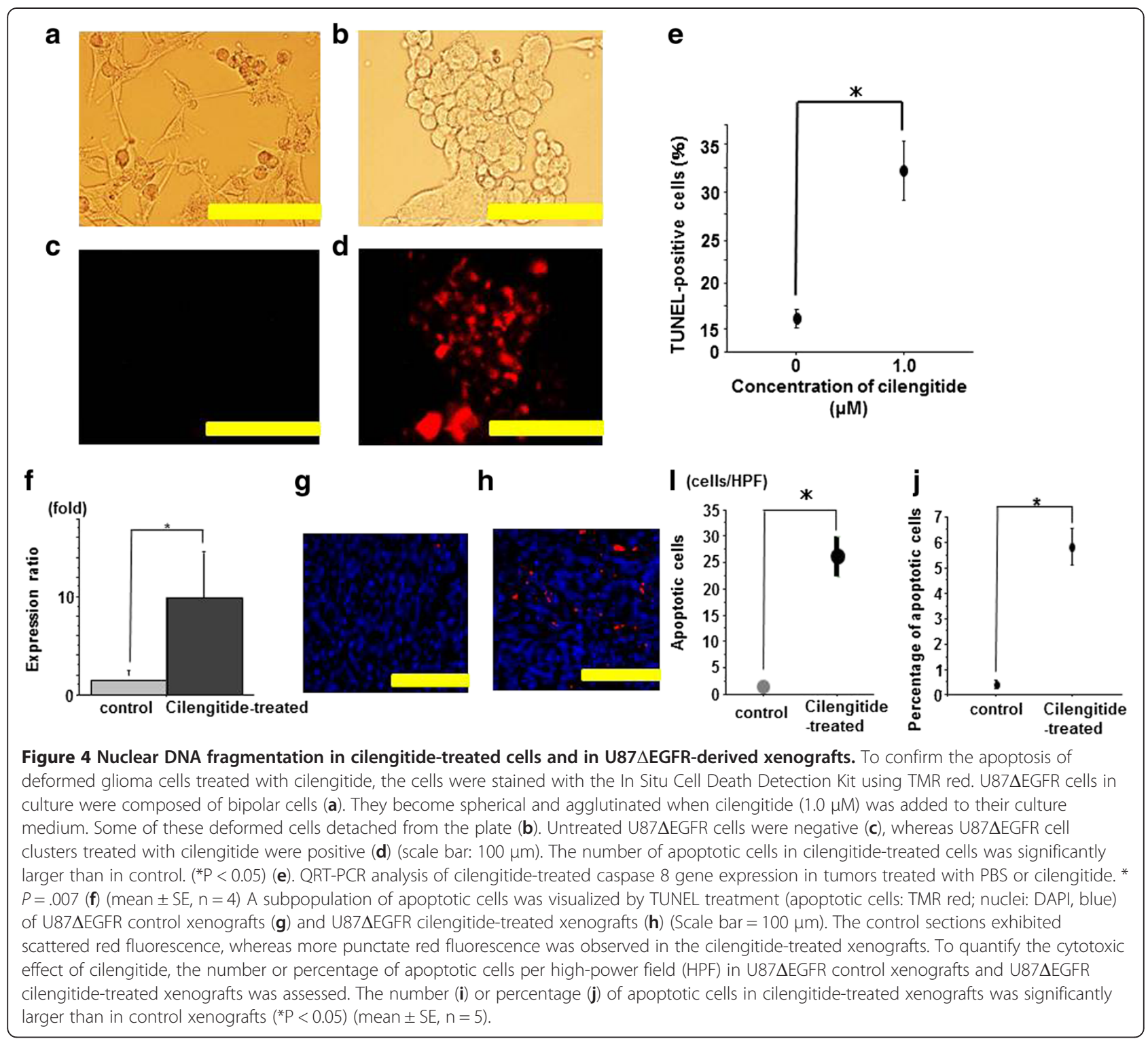

2000). Previously, we described the anti-invasive effect of cilengitide as its direct effect on glioma cells (Onishi et al. 2012) And we also reported the multiple mechanism of cilengitide for malignant glioma (Kurozumi et al. 2012).

Recent studies have shown that various cells are dependent on integrin-mediated adhesion to specific ECM proteins for their growth and survival and that detachment induces a form of apoptotic cell death recognized as anoikis (Chatterjee et al. 2000; Hynes 2002; OliveiraFerrer et al. 2008; Alghisi et al. 2009). Other studies reported that cilengitide exerts direct cytotoxic effects on glioma cells via an as yet unknown mechanism (Mikkelsen et al. 2009; Maurer et al. 2009; Oliveira-Ferrer et al. 2008). In this study, we examined the mechanism of cilengitideinduced cytotoxicity in glioma cells.

\section{Microarray analysis}

U87 $\triangle$ EGFR cells were chosen for gene chip analysis because they have a more aggressive phenotype than other cell lines. $\triangle E G F R$ confers enhanced tumorigenicity on duced apoptotic rates in vivo. It will be important and interesting if we conduct a newly found cell death signaling pathway via integrin stimulation in this aggressive cell line.

Our data using the most sophisticated DNA microarray to date, profiling over 57000 genes, revealed the mechanism underlying the anti-glioma effect of cilengitide. After cilengitide treatment of glioma cells, apoptosisrelated genes (i.e., caspase 8, desmoplakin, and protein kinase C, zeta) were upregulated. Apoptotic cleavage of glioblastoma cells through elevated proliferation and re- 
cellular proteins, FasL/CD95L signaling, TNF receptor signaling pathway, and ceramide signaling pathway were included in the significantly enriched molecular pathways.

Apoptosis is regulated by a series of biochemical events that commit a cell to death. A common feature of cells undergoing apoptosis is the activation of caspases, a family of aspartic acid-directed proteases (Alnemri et al. 1996). Caspases are activated during apoptosis and cleave specific proteins, resulting in the irreversible commitment to cell death. The signal transduction proteins MEKK1, p21activated kinase 2, and focal adhesion kinase are caspase substrates that contribute to the cell death response when cleaved.

FasL (CD95L) is a tumor necrosis factor (TNF)-related type II membrane protein (Suda et al. 1993). Fas (CD95) is a cell surface protein belonging to the TNF receptor superfamily, and is expressed in glioma cells (Husain et al. 1998). The binding of FasL to Fas induces the trimerization of Fas, and FADD (Fas associated via DD (death domain))/MORT1 binds to the trimerized FAS cytoplasmic region through the interaction of their respective DDs. Caspase-8 is then recruited to FADD/ MORT1 through binding of the DED (dead effector domain) domains, which in turn may induce the selfactivation of the protease domain (Nagata 1997).

TNF-R1-bound TRADD (TNF-receptor associated via DD) recruits FADD through DD interaction. In turn, FADD recruits procaspase- 8 or -10 , which are activated by proximity, via its DED. Protein kinase C, zeta, is also involved in the TNF receptor signaling pathway. Activation of caspase- 8 and -10 is sufficient to initiate a signaling cascade that induces apoptosis (Schneider-Brachert et al. 2004).

Recently, similar changes in human umbilical vein endothelial cells (HUVECs) have been reported for S 36578-2, a novel RGD mimetic that selectively activates the $\alpha v \beta 3$ and $\alpha v \beta 5$ integrins(Maubant et al. 2006). This compound induces cell detachment and apoptosis by the direct activation of caspase-8. Aoudjit and Vuori (Aoudjit \& Vuori 2001) reported that detachment-induced cell death in HUVECs resulted from the activation of the Fas pathway by FasL/Fas interaction, Fas-FADD complex formation, and caspase-8 activation. Previous reports on epithelial cells also documented the involvement of FADD and caspase-8 in detachment-induced apoptosis (Alghisi et al. 2009; Hynes 2002). Using human glioma cell lines expressing the $\alpha v \beta 3$ and $\alpha v \beta 5$ integrins, cilengitide caused a profound detachment and increase of apoptosis in glioma cells similar to what was observed in endothelial cells, suggesting that identical mechanisms might occur in both cell types (Oliveira-Ferrer et al. 2008).

\section{Clinical application of cilengitide for malignant glioma}

There have been several reports on the preliminary results of phase I and II trials of cilengitide for recurrent or newly diagnosed malignant glioma. Cilengitide monotherapy or combination treatment with radiation and/or temozolomide is well tolerated and exhibits modest antitumor activity (Reardon et al. 2008a; Reardon et al. 2008b; Nabors et al. 2012). According to our results, in addition to the anti-angiogenic and anti-invasion effects of cilengitide(Kurozumi et al. 2012; Onishi et al. 2012), the cytotoxic effect of cilengitide was clearly shown. cilengitide inhibited integrin binding and activated caspase-8. This caspase- 8 activation effect of cilengitide would enhance the effect of other cytotoxic therapies. Several preclinical studies have shown an enhanced antitumor effect of cilengitide when administered in combinatorial therapeutic regimens (Burke et al. 2002; Abdollahi et al. 2005; Tentori et al. 2008; Reardon et al. 2008a). Mikkelsen et al. demonstrated that cilengitide dramatically amplified the efficacy of radiation therapy in an animal glioma model (Mikkelsen et al. 2009). Kurozumi et al. demonstrated the enhanced therapeutic efficacy of an oncolytic virus on experimental glioma following pretreatment with cilengitide (Kurozumi et al. 2007).

\section{Conclusion}

We showed the cytotoxic effect of cilengitide on glioma cells. Microarray analysis revealed the detailed mechanism of the cytotoxic effect of cilengitide. Cilengitide, an inhibitor of integrins, activated caspase- 8 and induced apoptosis-related pathways.

\section{Competing interests}

The authors declare that they have no competing interests.

\section{Authors' contributions}

$\mathrm{MO}$ contributed to the experimental design, data collection, data analysis, data interpretation, and drafted the manuscript. KK initiated the project, data interpretation and drafted the manuscript. HM and YS carried out the Western blot analysis. KF carried out the activity assay of caspase. J carried out the QRT-PCR for in vivo. TI and ID participated data interpretation, and helped draft the manuscript. EAC and BK participated in planning the study. All authors read and approved the final manuscript.

\section{Acknowledgements}

We thank H. Wakimoto, M. Arao, and A. Ishikawa for their technical assistance. This study was supported by grants-in-aid for Scientific Research from the Japanese Ministry of Education, Culture, Sports, Science, and Technology to K.K. (No. 20890133; No. 21791364), and T.I. (No. 19591675; No. 22591611)

\section{Author details}

'Department of Neurological Surgery, Okayama University Graduate School of Medicine, Dentistry and Pharmaceutical Sciences, 2-5-1, Shikata-cho, Kitaku, Okayama 700-8558, Japan. ${ }^{2}$ Department of Physiology, Okayama University Graduate School of Medicine, Dentistry and Pharmaceutical Sciences, Okayama, Japan. ${ }^{3}$ Brigham and Women's Hospital, Neurosurgery, Boston, MA, USA. ${ }^{4}$ Department of Neurological Surgery, Dardinger Laboratory for Neuro-oncology and Neurosciences, The Ohio State University, Columbus, $\mathrm{OH}, \mathrm{USA}$.

Received: 19 December 2012 Accepted: 4 April 2013

Published: 15 April 2013 


\section{References}

Abdollahi A, Griggs DW, Zieher H, Roth A, Lipson KE, Saffrich R, Grone HJ, Hallahan DE, Reisfeld RA, Debus J, Niethammer AG, Huber PE (2005) Inhibition of alpha(v)beta3 integrin survival signaling enhances antiangiogenic and antitumor effects of radiotherapy. Clin Cancer Res 11 (17):6270-6279. doi:10.1158/1078-0432.CCR-04-1223

Albert JM, Cao C, Geng L, Leavitt L, Hallahan DE, Lu B (2006) Integrin alpha v beta 3 antagonist Cilengitide enhances efficacy of radiotherapy in endothelial cell and non-small-cell lung cancer models. Int J Radiat Oncol Biol Phys 65(5):1536-1543. doi:10.1016/j.jijobp.2006.04.036

Alghisi GC, Ponsonnet L, Ruegg C (2009) The integrin antagonist cilengitide activates alphaVbeta3, disrupts VE-cadherin localization at cell junctions and enhances permeability in endothelial cells. PLoS One 4(2):e4449. doi:10.1371/ journal.pone.0004449

Alnemri ES, Livingston DJ, Nicholson DW, Salvesen G, Thornberry NA, Wong WW, Yuan J (1996) Human ICE/CED-3 protease nomenclature. Cell 87(2):171. doi: S0092-8674(00)81334-3

Aoudjit F, Vuori K (2001) Matrix attachment regulates Fas-induced apoptosis in endothelial cells: a role for c-flip and implications for anoikis. J Cell Biol 152 (3):633-643

Brooks PC, Clark RA, Cheresh DA (1994a) Requirement of vascular integrin alpha v beta 3 for angiogenesis. Science 264(5158):569-571

Brooks PC, Montgomery AM, Rosenfeld M, Reisfeld RA, Hu T, Klier G, Cheresh DA (1994b) Integrin alpha $\vee$ beta 3 antagonists promote tumor regression by inducing apoptosis of angiogenic blood vessels. Cell 79(7):1157-1164. doi:0092-8674(94)90007-8

Burke PA, DeNardo SJ, Miers LA, Lamborn KR, Matzku S, DeNardo GL (2002) Cilengitide targeting of alpha(v)beta(3) integrin receptor synergizes with radioimmunotherapy to increase efficacy and apoptosis in breast cancer xenografts. Cancer Res 62(15):4263-4272

Chatterjee S, Matsumura A, Schradermeier J, Gillespie GY (2000) Human malignant glioma therapy using anti-alpha(v)beta3 integrin agents. J Neurooncol 46(2):135-144

Friedlander M, Brooks PC, Shaffer RW, Kincaid CM, Varner JA, Cheresh DA (1995) Definition of two angiogenic pathways by distinct alpha $v$ integrins. Science 270(5241):1500-1502

Hodivala-Dilke KM, Reynolds AR, Reynolds LE (2003) Integrins in angiogenesis: multitalented molecules in a balancing act. Cell Tissue Res 314(1):131-144. doi:10.1007/s00441-003-0774-5

Husain N, Chiocca EA, Rainov N, Louis DN, Zervas NT (1998) Co-expression of Fas and Fas ligand in malignant glial tumors and cell lines. Acta Neuropathol 95 (3):287-290

Hynes RO (2002) Integrins: bidirectional, allosteric signaling machines. Cell 110 (6):673-687. doi:S0092867402009716

Ichii O, Otsuka S, Namiki Y, Hashimoto Y, Kon Y (2011) Molecular pathology of murine ureteritis causing obstructive uropathy with hydronephrosis. PLoS One 6(11):e27783. doi:10.1371/journal.pone.0027783PONE-D-11-14494

Kambara H, Okano H, Chiocca EA, Saeki Y (2005) An oncolytic HSV-1 mutant expressing ICP34.5 under control of a nestin promoter increases survival of animals even when symptomatic from a brain tumor. Cancer Res 65(7):28322839. doi:10.1158/0008-5472.CAN-04-3227

Kurozumi K, Tamiya T, Ono Y, Otsuka S, Kambara H, Adachi Y, Ichikawa T, Hamada H, Ohmoto T (2004) Apoptosis induction with 5-fluorocytosine /cytosine deaminase gene therapy for human malignant glioma cells mediated by adenovirus. J Neurooncol 66(1-2):117-127

Kurozumi K, Hardcastle J, Thakur R, Yang M, Christoforidis G, Fulci G, Hochberg FH, Weissleder R, Carson W, Chiocca EA, Kaur B (2007) Effect of tumor microenvironment modulation on the efficacy of oncolytic virus therapy. J Natl Canc Inst 99(23):1768-1781. doi:10.1093/jnci/djm229

Kurozumi K, Ichikawa T, Onishi M, Fujii K, Date I (2012) Cilengitide treatment for malignant glioma: current status and future direction. Neurol Med Chir (Tokyo) 52(8):539-547. doi:DN/JST.JSTAGE/nmc/52.539

Leavesley DI, Ferguson GD, Wayner EA, Cheresh DA (1992) Requirement of the integrin beta 3 subunit for carcinoma cell spreading or migration on vitronectin and fibrinogen. J Cell Biol 117(5):1101-1107

MacDonald TJ, Taga T, Shimada H, Tabrizi P, Zlokovic BV, Cheresh DA, Laug WE (2001) Preferential susceptibility of brain tumors to the antiangiogenic effects of an alpha(v) integrin antagonist. Neurosurgery 48(1):151-157

Maubant S, Saint-Dizier D, Boutillon M, Perron-Sierra F, Casara PJ, Hickman JA, Tucker GC, Van Obberghen-Schilling E (2006) Blockade of alpha $\vee$ beta3 and alpha $v$ beta5 integrins by RGD mimetics induces anoikis and not integrin- mediated death in human endothelial cells. Blood 108(9):3035-3044. doi:10.1182/blood-2006-05-023580

Maurer GD, Tritschler I, Adams B, Tabatabai G, Wick W, Stupp R, Weller M (2009) Cilengitide modulates attachment and viability of human glioma cells, but not sensitivity to irradiation or temozolomide in vitro. Neuro Oncol 11 (6):747-756. doi:10.1215/15228517-2009-012

Michiue H, Tomizawa K, Matsushita M, Tamiya T, Lu YF, Ichikawa T, Date I, Matsui $H$ (2005a) Ubiquitination-resistant p53 protein transduction therapy facilitates anti-cancer effect on the growth of human malignant glioma cells. FEBS Lett 579(18):3965-3969. doi:10.1016/j.febslet.2005.06.021

Michiue H, Tomizawa K, Wei FY, Matsushita M, Lu YF, Ichikawa T, Tamiya T, Date I, Matsui $\mathrm{H}$ (2005b) The NH2 terminus of influenza virus hemagglutinin-2 subunit peptides enhances the antitumor potency of polyarginine-mediated p53 protein transduction. J Biol Chem 280(9):8285-8289. doi:10.1074/jbc. M412430200

Mikkelsen T, Brodie C, Finniss S, Berens ME, Rennert JL, Nelson K, Lemke N, Brown SL, Hahn D, Neuteboom B, Goodman SL (2009) Radiation sensitization of glioblastoma by cilengitide has unanticipated schedule-dependency. Int J Cancer 124(11):2719-2727. doi:10.1002/ijc.24240

Nabors LB, Mikkelsen T, Rosenfeld SS, Hochberg F, Akella NS, Fisher JD, Cloud GA, Zhang Y, Carson K, Wittemer SM, Colevas AD, Grossman SA (2007) Phase I and correlative biology study of cilengitide in patients with recurrent malignant glioma. J Clin Oncol 25(13):1651-1657. doi:10.1200/ JCO.2006.06.6514

Nabors LB, Mikkelsen T, Hegi ME, Ye X, Batchelor T, Lesser G, Peereboom D, Rosenfeld MR, Olsen J, Brem S, Fisher JD, Grossman SA (2012) A safety run-in and randomized phase 2 study of cilengitide combined with chemoradiation for newly diagnosed glioblastoma (NABTT 0306). Cancer. doi:10.1002/cncr.27585

Nagata S (1997) Apoptosis by death factor. Cell 88(3):355-365. doi:S0092-8674(00) 81874-7

Narita Y, Nagane M, Mishima K, Huang HJ, Furnari FB, Cavenee WK (2002) Mutant epidermal growth factor receptor signaling down-regulates p27 through activation of the phosphatidylinositol 3-kinase/Akt pathway in glioblastomas. Cancer Res 62(22):6764-6769

Oliveira-Ferrer L, Hauschild J, Fiedler W, Bokemeyer C, Nippgen J, Celik I, Schuch $G$ (2008) Cilengitide induces cellular detachment and apoptosis in endothelial and glioma cells mediated by inhibition of FAK/src/AKT pathway. J Exp Clin Cancer Res 27:86. doi:10.1186/1756-9966-27-86

Onishi M, Ichikawa T, Kurozumi K, Fujii K, Yoshida K, Inoue S, Michiue H, Chiocca EA, Kaur B, Date I (2012) Bimodal anti-glioma mechanisms of cilengitide demonstrated by novel invasive glioma models. Neuropathology. doi:10.1111/j.1440-1789.2012.01344.x

Reardon DA, Fink KL, Mikkelsen T, Cloughesy TF, O'Neill A, Plotkin S, Glantz M, Ravin P, Raizer JJ, Rich KM, Schiff D, Shapiro WR, Burdette-Radoux S, Dropcho EJ, Wittemer SM, Nippgen J, Picard M, Nabors LB (2008a) Randomized phase II study of cilengitide, an integrin-targeting arginine-glycine-aspartic acid peptide, in recurrent glioblastoma multiforme. J Clin Oncol 26(34):5610-5617. doi:10.1200/JCO.2008.16.7510

Reardon DA, Nabors LB, Stupp R, Mikkelsen T (2008b) Cilengitide: an integrintargeting arginine-glycine-aspartic acid peptide with promising activity for glioblastoma multiforme. Expert Opin Investig Drugs 17(8):1225-1235. doi:10.1517/13543784.17.8.1225

Schneider-Brachert W, Tchikov V, Neumeyer J, Jakob M, Winoto-Morbach S, HeldFeindt J, Heinrich M, Merkel O, Ehrenschwender M, Adam D, Mentlein R, Kabelitz D, Schutze S (2004) Compartmentalization of TNF receptor 1 signaling: internalized TNF receptosomes as death signaling vesicles. Immunity 21 (3): 415-428. doi:10.1016/j.immuni.2004.08.01751074761304002341

Stupp R, Weber DC (2005) The role of radio- and chemotherapy in glioblastoma. Onkologie 28(6-7):315-317. doi:10.1159/000085575

Suda T, Takahashi T, Golstein P, Nagata S (1993) Molecular cloning and expression of the Fas ligand, a novel member of the tumor necrosis factor family. Cell 75(6):1169-1178. doi:0092-8674(93)90326-L

Tentori L, Dorio AS, Muzi A, Lacal PM, Ruffini F, Navarra P, Graziani G (2008) The integrin antagonist cilengitide increases the antitumor activity of temozolomide against malignant melanoma. Oncol Rep 19(4):1039-1043

Tucker GC (2003) Alpha v integrin inhibitors and cancer therapy. Curr Opin Investig Drugs 4(6):722-731

Varner JA, Cheresh DA (1996a) Integrins and cancer. Curr Opin Cell Biol 8(5):724730. doi:S0955-0674(96)80115-3

Varner JA, Cheresh DA (1996b) Tumor angiogenesis and the role of vascular cell integrin alphavbeta3. Important Adv Oncol:69-87 
Varner JA, Emerson DA, Juliano RL (1995) Integrin alpha 5 beta 1 expression negatively regulates cell growth: reversal by attachment to fibronectin. $\mathrm{Mol}$ Biol Cell 6(6):725-740

Xiong JP, Stehle T, Diefenbach B, Zhang R, Dunker R, Scott DL, Joachimiak A, Goodman SL, Arnaout MA (2001) Crystal structure of the extracellular segment of integrin alpha Vbeta3. Science 294(5541):339-345. doi:10.1126/ science. 10645351064535

Yoshino K, Motoyama S, Koyota S, Shibuya K, Usami S, Maruyama K, Saito H, Minamiya Y, Sugiyama T, Ogawa J (2011) IGFBP3 and BAG1 enhance radiation-induced apoptosis in squamous esophageal cancer cells. Biochem Biophys Res Commun 404(4):1070-1075. doi:10.1016/j.bbrc.2010.12.115

doi:10.1186/2193-1801-2-160

Cite this article as: Onishi et al:: Gene expression profiling of the antiglioma effect of Cilengitide. SpringerPlus 2013 2:160.

Submit your manuscript to a SpringerOpen ${ }^{\circ}$ journal and benefit from:

- Convenient online submission

- Rigorous peer review

- Immediate publication on acceptance

- Open access: articles freely available online

- High visibility within the field

- Retaining the copyright to your article

Submit your next manuscript at $>$ springeropen.com 